\title{
Aproximación al papel de la mujer en la institución notarial malagueña en la primera mitad del siglo XVIII: la fémina como propietaria, transmisora y señora del oficio
}

Lorena Catalina Barco Cebrián

Universidad de Málaga 



\title{
Aproximación al papel de la mujer en la institución notarial malagueña en la primera mitad del siglo XVIII: la fémina como propietaria, transmisora y señora del oficio
}

\section{Approach to the role of women in the notarial institution of Malaga in the first half at the XVIIIth century: the female as owner, sender and property}

\author{
Lorena Gatalina Barco Cebrián \\ Universidad de Málaga \\ lbarco@uma.es
}

Fecha de recepción: 23/03/2017

Fecha de aceptación: 11/07/17

\section{Resumen}

La institución notarial ha sido analizada y estudiada desde la década de los ochenta del siglo pasado desde múltiples perspectivas; sin embargo, el papel desempeñado por la mujer en su seno ha sido obviado por la historiografía. Únicamente algunos autores lo han analizado de forma tangencial en trabajos más amplios sobre el notariado español. Por ello, en el presente trabajo centraremos nuestro análisis en el papel de la mujer como propietaria, señora y transmisora de este oficio en la primera mitad del siglo XVIII en la provincia malacitana. Para ello hemos utilizado la documentación correspondiente al Catastro de Ensenada y la documentación local custodiada tanto en el Archivo Municipal de Málaga como en el Archivo Histórico Provincial de la misma capital.

Palabras clave: Mujer; Institución notarial; Málaga; Siglo XVIII

\begin{abstract}
The notarial institution has been analyzed from the decade of the eighties of the last century from multiple perspectives; however, the role played by the woman in the institution has been obviated by historiography. Only a few authors have studied it tangentially in larger works about Spanish notary. Therefore, in the present work we will focus our analysis on the role of woman as owners, sender and property of this job in the XVIIIth century to the province of Malaga. For this, we have used the documentation corresponding to the Cadastre of Ensenada and the local documentation kept both in the Municipal Archive of Malaga and in the Provincial Historical Archive of the same capital.
\end{abstract}

Keywords: Woman; Notarial institution; Malaga; XVIIIth century 
Para citar este artículo: Barco Cebrián, L. C. (2017). Aproximación al papel de la mujer en la institución notarial malagueña en la primera mitad del siglo XVIII: la fémina como propietaria, transmisora y señora del oficio. Revista de Humanidades, n. 32, p. 25-44, ISSN 2340-8995 (ISSN-e 2340-8995).

SUMARIO: 1. Introito. 2. La mujer en el seno del notariado malagueño en la primera mitad del siglo XVIII: transmisora y señora de bienes como madre, hija, esposa, hermana... 3. A modo de colofón. 4. Bibliografía.

\section{INTROITO}

El análisis del papel desempeñado por la mujer a lo largo de la Historia es un tema que está en auge desde hace algunas décadas, concretamente desde que el Feminismo se alzara en voz de muchas mujeres allá por la década de los 70 del siglo pasado (Segura, 1992, pp. 139-151; Segura, 2008b, pp. 274-292; Segura, 2008a, pp. 249-272; Krauel, 1992; Fuster, 2009, pp. 247-273; Suárez, 2003). Desde entonces y hasta nuestros días han sido numerosos los trabajos que versan sobre diversos aspectos que históricamente han envuelto a la mujer desde la Antigüedad hasta la Contemporaneidad (Val Valdivieso, 2004; Morant, 2005; Calero y Francia, 2003). En la línea de ampliación del espectro a analizar dentro de la Historia de las Mujeres, en las sucesivas páginas intentaremos dar a conocer una parcela de la Historia que no ha sido tratada en profundidad, nos referimos al análisis del papel que desempeñó la mujer del siglo XVIII dentro de una institución tan varonil como fue la notarial. El oficio de escribano era ejercido en exclusividad por varones; no obstante, la mujer podía aunar en su persona varios privilegios en lo relativo a dicho oficio. La fémina, en multitud de ocasiones, se convertía en heredera de algún escritorio; o bien, recibía como dote para su matrimonio la propiedad; e, incluso, podía designar al escribano como tutora de sus hijos. Todo ello, nos lleva a analizar las posibles vías de relación entre la mujer y la institución notarial para la provincia malagueña en la primera mitad del siglo XVIII.

Elegimos la horquilla cronológica aducida porque en su seno se produjo una fuente documental que creemos de gran utilidad para poder resolver positivamente la hipótesis planteada, nos referimos a las pesquisas surgidas a raíz del denominado como Catastro de Ensenada. A través de las Respuestas Generales custodiadas en el Archivo General de Simancas, referentes a los 103 municipios $^{1}$ que actualmente

1 Alameda, Alcaucín, Alfarnate, Alfarnatejo, Algarrobo, Algatocín, Alhaurín de la Torre, Alhaurín el Grande, Almáchar, Almargen, Almogía, Álora, Alozaina, Alpandeire, Antequera, Árchez, Archidona, Ardales, Arenas, Arriate, Atajate, Benadalid, Benahavís, Benalauría, Benalmádena, Benamargosa, Benamocarra, Benaoján, Benarrabá, El Borge, El Burgo, Campillos, Canillas de Aceituno, Canillas de Albaida, Cañete la Real, Carratraca, Cartajima, Cártama, Casabermeja, Casarabonela, Casares, Coín, Colmenar, Comares, Cómpeta, Cortes de la Frontera, Cuevas Bajas, Cuevas de San 
conforman la provincia malacitana, hemos podido acercarnos, sobre todo, a los nombres de los propietarios de los diferentes oficios escribaniles. Y, efectivamente, complementando dicha fuente con otra documentación albergada en diferentes archivos locales, hemos detectado que un número nada desdeñable de estos oficios pertenecía a mujeres o tenía una estrecha vinculación con ellas.

Como apuntáramos más arriba, ya desde la década de los 70 del siglo pasado se viene introduciendo en los estudios históricos la figura de la mujer, en lo que se ha denominado como Historia de las Mujeres (Segura, 1992. pp. 139-151; Segura, 2006, pp. 85-107). No obstante, y a pesar de lo mucho ya andado, habría que ir virando la concepción de una Historia de las Mujeres en particular, para avanzar hacia una Historia General, donde tengan cabida tanto hombres como mujeres, ya que el sujeto histórico es y ha sido tanto femenino como masculino (Barco, 2014; pp. 27-38). De ahí que si queremos tener una concepción global del mundo que rodea al fedatario también debamos hacer mención al papel desempeñado por las féminas dentro de esta institución.

Por otro lado, a pesar del gran avance cuantitativo que se ha producido en la historiografía relativa a la institución notarial (Arroyal et al., 2007; Rojas, 2004, pp. 573-584; Bono, 1979; Álvarez-Coca, 1987; pp. 555-564; Blasco, 1990; Moreno et al., 2011; Marchant, 2002; Extremera, 2011, pp. 23-39; Villalba y Torné, 2010; Arroyal y Ostos, 2014; Ostos y Pardo, 1995; Cózar, 2010, pp. 269-299; Rodríguez, 2001, pp. 131-150; Escudero, 2012, pp. 1337-1347; Montojo, 2008, pp. 7-28; Barco y Marchant, 2016; Artuña, 2014; Piñol, 2015; Calleja, 2015, pp. 59-82; Castro, 2017, pp. 69-76; Puñal, 2011, pp. 292-311; Domínguez, 2016), ya apuntaba D. Ángel Riesco Terrero (2003, p. 177) que ese aumento cuantitativo no ha ido acompañado de un aumento cualitativo, aunque por supuesto hay grandes excepciones. Pero lo que sí denunciaba el catedrático en Paleografía era la falta de un análisis global del notariado tanto geográfica como cronológicamente, trabajo que aún está por realizar. Esto también se puede relacionar con la falta de estudios que analicen la vinculación de la mujer con aquel grupo socio-profesional. A pesar de ello, es cierto que algunas autoras y autores sí que han tratado, aunque sea tangencialmente, a la mujer en la institución notarial (Marchant y Barco, 2017; Mendoza, 2007; Extremera, 2009; Escalante, 2016; Camino, 1998). Algo que se intenta paliar en las sucesivas páginas para la horquilla cronológica propuesta y el ámbito geográfico aducido.

\footnotetext{
Marcos, Cuevas del Becerro, Cútar, Estepona, Faraján, Frigiliana, Fuengirola, Fuente de Piedra, Gaucín, Genalguacil, Guaro, Humilladero, Igualeja, Istán, Iznate, Jimera de Líbar, Jubrique, Júzcar, La Viñuela, Macharaviaya, Málaga, Manilva, Marbella, Mijas, Moclinejo, Mollina, Monda, Montecorto, Montejaque, Nerja, Ojén, Parauta, Periana, Pizarra, Pujerra, Rincón de la Victoria, Riogordo, Ronda, Salares, Sayalonga, Sedella, Serrato, Sierra de Yeguas, Teba, Tolox, Torremolinos, Torrox, Totalán, Valle de Abdalajís, Vélez-Málaga, Villanueva de Algaidas, Villanueva de la Concepción, Villanueva de Tapia, Villanueva del Rosario, Villanueva del Trabuco y Yunquera.
} 


\section{LA MUJER EN EL SENO DEL NOTARIADO MALAGUEÑO EN LA PRIMERA MITAD DEL SIGLO XVIII: TRANSMISORA Y SEÑORA DE BIENES GOMO MADRE, HIJA, ESPOSA, HERMANA...}

La mujer en la centuria de la Ilustración, y ya desde la implantación del notariado, no podía ejercer el oficio de fedatario por su condición biológica, el haber nacido mujer. No obstante, en el período bajomedieval, cuando se produce el auge de las universidades y con él un aumento en el número de escribanos que en dicha coyuntura veían un incremento de su trabajo, hay ejemplos de algunas amanuenses, concretamente dos, en los alrededores de la Universidad de Bolonia (Sánchez y Domínguez, 1999, p. 127). Estas excepciones tal vez no sean las únicas, sobre todo en el siglo XIII, centuria de iniciación de esta institución, pero no cabe duda de que con la consolidación del notariado la fémina se vio excluida de su ejercicio, lo que se vería refrendado por la legislación. Así uno de los requisitos para poder ejercer el oficio escribanil era ser hombre. Esta exigencia, ya recogida en las Partidas del Rey Sabio, era una cuestión inherente al oficio y que quedaba constantemente refrendada en la documentación:

“(...) una de las cláusulas de la perpetuidad del expresado oficio, que dispone que perteneciendo a muger o menor que no le pueda exerzer ella o su tutor y curador, tengan facultad en nombrar persona que lo haga en el ynterin, que el menor tiene hedad o la muger toma estado (...)"2.

Sin embargo, la mujer sí que tuvo una dimensión dentro de aquel oficio liberal (Marchant y Barco, 2017), no solo como rogataria, es decir, que era ella la que requería la intervención escrituraria del fedatario para que redactara cierto documento; sino, además, la mujer vehiculizaba en numerosas ocasiones el devenir de una escribanía.

El papel de la mujer en la transmisión del patrimonio familiar no es novedoso, y estuvo presente desde tiempos pretéritos en la tradición castellana. La mujer se convertía en transmisora de bienes y receptora a partes iguales de las herencias paternas y maternas, lo que hacía apetecible a ojos de muchos hombres desposarse con aquellas féminas que por herencia o dote recibían una escribanía en propiedad. Se trataba de mujeres, en este caso, con una elevada posición en la sociedad malagueña o castellana del momento, pertenecientes a familias de las élites locales que contaban, en la mayoría de las ocasiones, con un gran patrimonio y peso entre sus conciudadanos.

Por lo tanto, la vinculación de la mujer con la institución notarial se podía establecer de múltiples formas. Por un lado, podía ser hija de un notario y convertirse en heredera del oficio en cuestión. Por otro lado, podía ser mujer de un fedatario y, de igual forma, heredar dicho escribanía. Como hermana también podría llegar a ser

2 (A)rchivo, (M)unicipal de (M)álaga, Libro de Reales Provisiones, Vol. 89, f. 267r. 
propietaria del oficio si su hermano fallecía sin ningún tipo de descendencia directa y su madre había fallecido. De igual forma nos encontramos con el papel de la viuda como propietaria de un oficio escribanil, además de tutora de los hijos habidos en el matrimonio menores de edad y futuros propietarios o incluso ejercientes del oficio. Cabe también la posibilidad de que estas mujeres fueran propietarias del oficio de fedatario cuando pertenecían al estamento nobiliario. En este caso actuaban como dueñas y señoras del oficio, al igual que sus colegas varones. Toda esta casuística es la que vamos a analizar en las sucesivas páginas.

\subsection{El matrimonio como vehículo para ejercer el oficio de fedatario}

El matrimonio era desde la Edad Media (Carlé, 1980, pp. 115-177) una estrategia familiar para asegurar el poder y establecer alianzas entre linajes o consolidarlos (Lora, 2002, pp. 187-216). En pleno siglo XVIII el matrimonio también era un sistema de garantía social para la mayoría de las mujeres que accedían a él (Ortego, 2000 , pp. 62 y ss.). La red social impuesta en la época únicamente permitía que una mujer fuera honrada y respetable si se casaba o entraba a formar parte de una orden religiosa, es decir, se casaba con Dios. El matrimonio, por lo tanto, pasaba a ser un acuerdo entre familias, en la mayoría de los casos, donde ambas partes unían sus bienes. Esta unión sacramental fue importante en el seno de la institución notarial porque en no pocas ocasiones la mujer llevaba como dote matrimonial un oficio escribanil; generalmente, heredado por vía paterna. En estas ocasiones el futuro marido era el que ejercería dicho oficio, por lo que el enlace matrimonial era muy beneficioso para el novio, ya que se garantizaba un oficio bastante lucrativo y donde ejercería un poder y control sobre la sociedad a través de la escrituración notarial.

Claro ejemplo de utilización de un matrimonio para acceder al oficio de escribano fue el caso de Francisco Agustín de la Peña y Oña, fedatario del cabildo y de millones de la villa de Coín. Este fedatario accedió a la primera de las mencionadas escribanías gracias al matrimonio contraído con una de las hijas de María Benítez del Castillo, su propietaria; a su muerte, pasó dicha propiedad a sus herederos, entre los que se encontraba la mujer del referido fedatario ${ }^{3}$. En este caso se mezcla propiedad y herencia femenina. Por un lado, la propietaria era la madre de la esposa y, por otro lado, el escribano accede al oficio gracias a su enlace matrimonial con la heredera del mismo.

En la capital malacitana hallamos para esta época a dos mujeres que ostentaron la propiedad de sendas escribanías, según las pesquisas recogidas en el Catastro de Ensenada. Uno de los casos fue el de Antonia López Bueno, la cual era propietaria de una de las veinticuatro escribanías públicas de la ciudad malagueña, que era ejercida

3 (A)rchivo (G)eneral de (S)imancas, Dirección General de Rentas, Catastro de Ensenada, Respuestas Generales, Libro 285, fs. 107r-107v. 
por Luis Jerónimo Pizarro 4 . Este caso resulta cuanto menos curioso. Antonia López Bueno se casó en primeras nupcias con Francisco Gregorio Ruiz y Ordas, escribano público de la capital malacitana. Cuando este falleció se repartieron sus bienes entre sus herederos y, a su viuda, la mencionada Antonia, le correspondió la escribanía pública en satisfacción de sus dotes matrimoniales, que ascendieron a 8.400 reales de vellón. Antonia casó en segundas nupcias con Ángel Pérez de Velasco, por lo tanto sobre él recaería la disposición del oficio, ya que la mujer disponía del oficio hasta que volvía a contraer matrimonio. Sin embargo, Antonia no corrió mucha suerte en sus enlaces matrimoniales, el primero falleció y el segundo la abandonó. El mencionado Ángel Pérez se fue de la ciudad, lo que conllevaba que fuera ella de nuevo la que obtuviera la potestad del oficio. En este caso Antonia practicó su derecho de nombrar a escribano interino para que ejerciera el oficio, y así designó de nuevo al aducido Luis Jerónimo Pizarro en el año $1747^{5}$ :

“(...) y ahora por parte de vos, Luis Gerónimo Pizarro, mi escriuano aprouado, me ha sido hecha relazión, que por fallecimiento de dicho, Francisco Gregorio Ruíz y Ordas, se hizieron quentas y particiones de sus vienes, y entre ellos dicho oficio, el qual se adjudicó a Doña Antonia Lopes Bueno, su viuda, en parte del pago y zatisfación de su dote y por precio de ocho mill y quatrosientos reales vellón (...) pasado esta a segundas numpcias con Ángel Pérez de Velasco, y auientándose (sic) este de dicha ciudad sin que hasta ahora se sepa de su paradero por la justicia (...) la referida doña Antonia López Bueno (...) como propietaria de dicho oficio, en virtud de la referida auilitación, y de una de las cláusulas de la perpetuidad del que dispone que pertenesiente a muger, que no le pueda ejercer, tenga facultad de nombrar persona que le sirua (...)" ${ }^{\prime 6}$.

El segundo ejemplo al que hacíamos referencia es el de Juana Caballero, propietaria de la escribanía del número malacitano ejercida por Juan Fernández $\mathrm{Palao}^{7}$, sin embargo, no conocemos mucho más acerca de este oficio en cuestión.

Otro ejemplo que localizamos en la capital malagueña donde la mujer sirvió de vehículo para acceder a una escribanía fue el caso de José Muñoz Vallejo. Este accedió a uno de las escribanías públicas de la capital gracias a su matrimonio con Isabel Nieto Villavicencio. El citado oficio era propiedad del padre de esta última, Juan Félix González Nieto, pero cuando este falleció sus bienes se repartieron entre sus hijos y herederos, a saber: Francisco Nieto Villavicencio, doña Antonia, Lorenza, Isabel y Juana Nieto Villavicencio. A cada uno les correspondió una parte de sus bienes, y se estipuló que a su hija Isabel se le consignara como dote

4 Ibídem, Libro 295, f. 116v.

5 A.M.M., Libro de Reales Provisiones, Vol. 89, fs. 201r-203v.

6 A.M.M., Libro de Reales Provisiones, Vol. 89, fs. 201r-v.

7 A.G.S., Dirección General de Rentas, Catastro de Ensenada, Respuestas Generales, Libro 295 , f. $116 \mathrm{v}$. 
matrimonial la propiedad del mencionado oficio público. Así este pasó a manos de su marido, el tal José Muñoz Vallejo, quien pudo acceder y ejercer como uno de los veinticuatro fedatarios públicos de la capital malacitana, oficio deseado y codiciado por muchos, y que él consiguió gracias a su enlace matrimonial con la referida Isabel Nieto $^{8}$ :

“(...) auiendo fallecido auintestato el dicho, Juan Félix Gonsalez Nieto, por la justicia ordinaria de la dicha ciudad, se declaró por sus hijos y herederos, y del dicho oficio a Don Francisco Nieto Vella Vesencio, doña Antonia, doña Lorenza, doña Ysauel y doña Juana Nieto Villa Visencio, entre los quales auiéndose echa quentas y partiziones, en treinta de agosto de mil setecientos y treinta, se adjudicó el zitado oficio a la dicha doña Ysauel Nieto Villa Visencio, vuestra muger, empago de su legítima paterna y materna (...)"9.

\subsection{La viuda como tutora y administradora de bienes}

El estado civil de viudedad podía afectar tanto a hombres como a mujeres en la Edad Moderna, sin embargo, cuando se habla de viudedad para estas fechas siempre se piensa en el género femenino. Obviamente esto se debe al mayor número de viudas frente a viudos en la sociedad moderna y para la fecha cronológica que aquí tratamos (García, 2016, pp. 293-295). La viuda tenía que hacerse cargo de la unidad familiar, en muchas ocasiones la mujer viuda se quedaba a cargo de los hijos habidos en el matrimonio, lo que podía conllevar a su aislamiento social por falta de una base económica para su mantenimiento. Esto se tradujo en que la viudedad se convirtió en muchas esferas sociales en un claro signo de exclusión, al quedar sin un referente y apoyo masculino dentro de una sociedad fuertemente patriarcal. Este hecho se podía solventar si la mujer contaba con una posición social y económica alta y solvente. En el caso que nos ocupa, la viuda que obtenía un oficio de fedatario tenía una posibilidad de salir de esa mencionada exclusión. Si el oficio lo había aportado ella como dote matrimonial se le devolvía su propiedad y actuaba como dueña y señora del mismo. En el caso de que el oficio llegara por herencia de su marido, generalmente ella se erigía en propietaria del mismo hasta que alguno de sus hijos cumplía la mayoría de edad y se hacía cargo de él, bien como propietario del mismo o ejerciéndolo si había superado el examen preceptivo para poder ejercer el oficio (Pardo, 1993, pp. 303-310; Domínguez, 2013, pp. 57-62). De una forma u otra, en el caso que nos atañe aquí la viuda se convertía en señora, administradora y transmisora del oficio escribanil ${ }^{10} ; \mathrm{y}$, como tal, podía optar por tomar dos decisiones. Por un lado, podía quedarse el oficio y nombrar a un interino que lo ejerciera. Y, por

8 A.M.M., Libro de Reales Provisiones, Vol. 88, fs. 792r-793v.

9 Ibídem.

10 No trataremos aquí la participación de la viuda en la escrituración notarial, para ello ver Marchant y Barco (2017). 
otro lado, podía venderlo y así obtener un montante bastante sustancioso de dinero líquido para poder afrontar la situación económica en la que se pudiera encontrar.

Como ejemplo, María Cueto y Traba era dueña de una escribanía pública de Antequera, la cual adquirió por ser la viuda de su anterior propietario, Miguel de Talavera ${ }^{11}$. Tal y como hemos referido anteriormente, en la mayoría de las ocasiones, la mujer mantenía la propiedad hasta que uno de los hijos, si los tuviera, fuera mayor de edad, o bien la viuda en cuestión volvía a contraer matrimonio. En este último caso, la propiedad podía pasar al nuevo cónyuge ya que al ser un bien cotizado entraba dentro de las dotes matrimoniales. Así queda reflejado en la documentación “(...) tengan facultad en nombrar persona que lo haga en el ynterin que el menor tiene hedad o la muger toma estado (...)"12.

Otro caso fue el de la escribanía servida por Jerónimo de Montes. Este había fallecido y en su testamento dejó por herederos a sus hijos, Pedro, Antonio, Jerónimo y Joseph Montes Urbano, junto con su mujer, María Urbano. Esta sería la tutora y curadora de los niños, menores de edad a la muerte del escribano numerario. A los infantes se les asignó un curador, como era habitual en la época, este fue Tomás Jerónimo de Jaraveytia. Ambos, madre y curador, en nombre tanto de los niños como de la propia María Urbano, acordaron vender la escribanía pública a Joseph Benítez Méndez de Sotomayor, quien accedió a ella en el año 1750. El montante de la venta del oficio se elevó hasta los tres mil ducados de vellón ${ }^{13}$. En este caso la mujer llega a ser propietaria del oficio una vez fallecido el marido y porque sus hijos son menores, lo que le convertía en tutora de los pequeños, decidiendo ella misma qué hacer con el mencionado oficio. Bien podía quedárselo y nombrar a un escribano interino hasta la mayoría de edad de uno de los hijos, o bien podía venderlo. En este caso, María Urbano se decide por la segunda opción, quizás movida por la necesidad de contar con dinero líquido para afrontar la crianza de cuatro niños.

Otro caso lo hallamos en la escribanía que servía Felipe Martínez de Valdivia, quien a su muerte dejó como herederos a sus hijos, todos ellos menores, los cuales eran Miguel, Francisco y Joseph Martínez de Valdivia. Sin embargo, su mujer estaba embarazada cuando se produjo el óbito, por lo tanto la criatura que nacería póstuma también sería heredera. En este caso, fue una niña, María Josepha Polonia Martínez de Valdivia, quien desafortunadamente murió a los siete meses de edad. Por lo tanto, la parte que le correspondía a la mencionada niña pasó a manos de su madre, María de Ávila. Esta como tutora de sus hijos y propietaria de una de las partes del oficio público que había servido su marido, decidió nombrar a un escribano interino que sirviera en el escritorio hasta que alguno de sus hijos fuera mayor de edad y pudiera ejercer el oficio. Tuvo que hacerlo junto con el curador que se le asignó a los menores,

11 A.G.S., Dirección General de Rentas, Catastro de Ensenada, Respuestas Generales, Libro 560, f. 237 r.

12 A.M.M., Libro de Reales Provisiones, Vol. 89, f. 267 r.

13 Ibídem, Libro de Reales Provisiones, Vol. 89, fs. 307v-313r. 
en este caso Ignacio Bernardo del Rey y Salazar. Ambos convinieron en nombrar como escribano interino a Antonio de Amorín y Díaz en el año 1749.

La escribanía que ejerció Diego Zazo y Linares también es ejemplo de cómo la mujer actuaba en el seno de la institución notarial. El escritorio público perteneció al padre del mencionado Diego, Manuel Zazo de Acuña. A la muerte de este se hicieron inventarios de sus bienes, y su mujer y viuda, madre del referido Diego Zazo, María de Arias y Linares, quiso que se le adjudicara en satisfacción de sus dotes matrimoniales la mencionada escribanía pública. Y así se hizo, después de inventariar los bienes del fallecido Manuel Zazo de Acuña, se resolvió que la propiedad del oficio de escribano recayera en su viuda. Una vez obtenida la propiedad, María de Arias y Linares lo que hizo fue ceder el oficio a su hijo, Diego Zazo y Linares, quien lo ejerció desde aquel momento -año de 1740- hasta su fallecimiento ${ }^{14}$ :

“(...) aora por parte de vos, Diego Zazo Linares, me a sido echa relazión que hauiendo fallesido el dicho Manuel de Zazo de Acuña, vuestro padre, se hizo ymuentario y tazazión de sus vienes. En cuio estado se acudió ante la justicia de la dicha ziudad por doña María de Arias y Linares, vuestra madre, pretendiendo se le diese satisfazión de su dote y que desde luego se le adjudicare en parte y pago de él, el mencionado oficio de escriuano del número que pertenesía a la herensia. Y con efectto, por auto de treinta de octubre de mill setezientos y treinta y nueue, proueido por el lizenciado, don Pedro Antonio Muños y Games, alcalde maior de la dicha ziudad, se hiso la adjudicación en comformidad de los consentimientos (...) el dicho oficio en cuia consequencia la expresada doña María de Arias y Linares, vuestra madre, por escriptura que otorgó en la dicha ziudad de Málaga a nueue de marzo de este año, ante Juan Afán de Riuera, mi escriuano, os sedió el dicho oficio en quenta y parte de la lexítima materna, que por su fin y muerte os hubiere de pertenecer (...)" ${ }^{\prime 15}$.

Pero la actuación de María de Arias no se circunscribió únicamente a lo referido más arriba en referencia al aducido oficio. El mencionado escribano e hijo de la susodicha, Diego Zazo y Linares, falleció soltero tan solo a los dos años de acceder al oficio, sin dejar descendencia, por lo que el escritorio pasó de nuevo a su madre como única heredera. Esta como propietaria del oficio decidió venderlo ejerciendo su derecho. Así lo hizo por veintitrés mil novecientos reales de vellón a Jacinto Espinosa de los Monteros ${ }^{16}$, quien pasó a ser uno de los veinticuatro escribanos numerarios de la capital malagueña en el año 1742:

“(...) hauiendo fallecido auintestato el expresado Diego de Zazo y Linares, recaió su propiedad del dicho oficio en Doña María de Arias y Linares, su madre, como

14 A.M.M., Libro de Reales Provisiones, fs. 788r-791r.

15 Ibídem, fs. 788r-789r.

16 A.M.M., Libro de Reales Provisiones, Vol. 89, fs. 9r-12v. 
su heredera única, mediante a auer fallecido en el estado de soltero. La qual por escriptura que otorgó en la referida ziudad dicha, Málaga, a veinte y tres de febrero deste año, ante Joseph Díez de Midina, mi escriuano, os vendió el mencionado oficio en precio de veinte y tres mil y nuebezientos reales de vellón (...) ${ }^{\text {17 }}$.

En este caso vemos que una misma mujer se relaciona con la institución notarial de dos formas distintas. Por un lado, al quedar viuda reclama el oficio de escribano para ofrecérselo a su hijo y así perpetuar su linaje en este oficio. Pero desgraciadamente al fallecer su hijo sin herederos, el oficio recayó de nuevo en su madre viuda. Esta segunda relación con la institución notarial por parte de María de Arias es diferente a la primera, ya que al no tener otra descendencia, el oficio en sí ya no le iba a reportar beneficios a su familia; por ello, prefiere venderlo y así obtener dinero líquido. Esta decisión le sería más beneficiosa ante su nueva situación, puesto que se trataba de una viuda que además no contaba con un hijo varón que pudiera hacerse cargo de ella.

Ejemplosemejante alacabado de mencionar lo hallamos en la escribanía de Miguel Rengel, escribano del número de la capital malagueña. Este murió abintestato, por lo que su única heredera fue su madre viuda, Ángela Aldana. Se nombró como interino a Juan de Ortega Vallejo, pero este renunció al oficio transcurrido un tiempo, por lo que de nuevo Ángela Aldana se vio en la necesidad de nombrar a un nuevo escribano interino en el año 1726, y en este caso designó a tal fin a Marcelo Bracho de la Vega ${ }^{18}$ :

“(...) auiendo fallecido avintestato el dicho Miguel Rengel y declarádose por su única y unibersal heredera a doña Ángela Aldana, su madre viuda de don Juan Rengel, su marido y padre del dicho Miguel Rengel, por otro despacho del mismo consejo de veinte y dos de octubre de mill setezientos y doze, se mandó que Juan de Ortega Vallejo, siruiese el dicho ofizio por el tiempo de la viudedad de la dicha doña Ángela de Aldana. En conformidad de su nombramiento según más largo, en los citados despachos a que me refiero se contiene. Y ahora, por parte de vos, Marcelo Bracho de la Vega, mi escriuano me a sido hecha relazión que por que hecho desestimiento del expresado ofizio el mencionado, Juan de Ortega Vallejo, a causa de no poder continuar en el exerzisio de él, la referida, doña Ángela de Aldana, usando de su derecho (...) tenga facultad de nombrar persona que le sirba en el ínterin (...)"19.

\subsection{Otras actuaciones de féminas en el notariado malagueño}

Como hemos podido comprobar a lo largo de las páginas precedentes, la actuación y la vinculación de la mujer con la institución notarial no es algo baladí ni

17 Ibídem, Vol. 89, fs. 9v-10r.

18 Ibídem, Vol. 88, fs. 287r-288v.

19 A.M.M., Libro de Reales Provisiones, Vol. 88, fs. 287r-v. 
casual; sino que, por el contrario, su participación es amplia y sustancial. Lógicamente no hemos constatado la presencia de ninguna escribana o notaria; sin embargo, no sería descabellado pensar que al igual que ocurrió en los alrededores de Bolonia en la Edad Media, pudiéramos encontrarnos algún caso de mujer que ejerciera el oficio, quizás no como fedataria pública, pero sí como amanuense. De hecho, en la literatura hay referencias a escribanas, lo que podría ser sintomático de un reflejo de la realidad; también, encontramos el apelativo "la escribana" en algunos padrones ${ }^{20}$ y documentos. Pero, esa vinculación de practicante del oficio no ha sido posible contrastarla para la provincia malacitana en la horquilla cronológica tratada.

Por otra parte, sí que hemos localizado a la mujer como propietaria del oficio; además, hecho que se da de diferentes formas. Sabemos que la propiedad de estos oficios escribaniles era codiciada por parte de los nobles de la época, lo que es sintomático de los copiosos beneficios que reportaba tener una escribanía en propiedad, aunque no se ejerciera como tal fedatario. Dentro de la nobleza también nos encontramos mujeres que llegaron a ostentar títulos nobiliarios y fueron propietarias de escribanías. Ejemplo de ello lo encontramos en la figura de la Marquesa de Villena. Esta tenía en propiedad tanto la escribanía numeraria como de ayuntamiento de la villa de Monda $^{21}$, de igual forma sucedía con la escribanía de concejo de la villa de Tolox ${ }^{22}$.

En Mijas, las escribanías tanto de cabildo como del número las ejercía Juan Pérez Naranjo en secuestro, ya que pertenecían a la alcaidía de Josefa de Salamanca, las cuales le vinieron por herencia familiar ${ }^{23}$, aquí hallamos otra tipología más para la vinculación y el papel desempeñado por la fémina en la institución notarial de la provincia malagueña.

Nueva muestra de la importancia de tener en propiedad uno de estos oficios es el caso de la escribanía de cabildo de la villa de Benamargosa. La posesión de esta pasó a los hijos de su anterior escribano, donde todos ellos tenían una parte, y al tener dos hijas, estas también pasaron a ser copropietarias del mencionado escritorio junto a sus otros hermanos. Se dividió la propiedad de la siguiente forma: la mitad para Pascual Dionisio Criado, que fue el hermano que la ejerció; una octava parte para Ángela Criado, y otra parte igual para su hermana, María Criado; quedando una última octava parte para otro de los hermanos, Alejandro Criado. Este caso sería un ejemplo de cómo un oficio escribanil era de gran importancia en el seno de una familia, llegando a producirse repartimientos del mismo al no rechazar ninguno parte de su propiedad.

20 Por ejemplo, hay una tal Inés la Escribana, casada en Larruga, Eugenio (1791), Memorias políticas y económicas sobre los frutos, comercio, fábricas y minas de España, Tomo XIII, Madrid.

21 A.G.S., Dirección General de Rentas, Catastro de Ensenada, Respuestas Generales, Libro 293 , fs. $315 \mathrm{v}-316 \mathrm{r}$.

22 Ibídem, Libro 302, fs. 157v-158r.

23 Ibídem, Libro 296, fs. 144v-145r. 
Otro ejemplo lo hallamos en la persona de Josefa Damiana de Anaya, vecina de Málaga, que gozaba de la propiedad de la escribanía de millones de la villa de Cártama, la cual quedaba albergada dentro de la jurisdicción de la capital malacitana. En este caso desconocemos cómo llegó la propiedad a esta mujer.

\section{A MODO DE GOLOFÓN}

En todos los casos aquí presentados el ejercicio y la propiedad del oficio eran dos líneas divergentes. Estas mujeres propietarias nominaban a un escribano que pudiera ejercer el oficio -una vez ratificado por el monarca ${ }^{24}$ - por un período de tiempo determinado en el ínterin, lo que se ha denominado como lugartenencia (Rábade, 1992, pp. 211-228). Generalmente, cuando eran viudas del anterior escribano, ejercían la propiedad hasta que alguno de sus hijos cumplía la mayoría de edad para poder ejercerlo -los veinticinco años preceptivos para poder examinarse y conseguir el título de escribano ${ }^{25}$. Durante dicho período la propietaria podía designar a uno o a varios escribanos que se irían turnando en el ejercicio del oficio. En otros casos, cuando la escribanía se daba en dote o era parte de la herencia paterna, por lo general, esta situación conllevaba que el marido ejerciera el oficio, aunque la propiedad la siguiera manteniendo la mujer. Podemos apreciar, además, que la mayoría de estas circunstancias, es decir, que una mujer esté al frente de un escritorio, ya sea de una forma u otra, era más frecuente en la capital malagueña. Algo que no es de extrañar si tenemos en cuenta que era en la capital donde más escribanías se localizan y donde la fémina podía tener un peso mayor que en las zonas rurales.

Finalmente, en el caso de la Marquesa de Villena, al igual que se constata para el resto de los nobles que tienen en propiedad algún tipo de escribanía, aquella cumplía el mismo papel que un hombre. Es decir, el noble, sea hombre o mujer, no ejerce el oficio, sino que ostenta la propiedad y nomina a un escribano para que lo ejerza, o bien lo arrienda. Lo que es seguro es que tanto en un caso como en otro, el noble, sea del sexo que sea, obtenía beneficios de la propiedad del oficio de fedatario.

Como colofón, en la página siguiente, queremos ofrecer una tabla donde se exponen aquellas mujeres que poseían la propiedad, o parte de ella, de una escribanía en la provincia malacitana. Las fechas utilizadas han sido diferentes para la provincia y para la capital, en el primer caso nos hemos circunscrito a las fechas extremas de la realización del Catastro de Ensenada para la provincia (1751-1754); mientras que para la capital, se ha ampliado el lapso temporal a consecuencia del mayor volumen de documentación que se ha localizado. Así para esta última la fecha se retrotrae

24 Para llegar a ser escribano público se debía superar un examen y que el monarca emitiera el título correspondiente, el cual debía presentar el futuro escribano ante el cabildo de la ciudad para así entrar a formar parte de la nómina de fedatarios del número de dicho lugar (Mendoza, 2007: 13, 17-27).

25 Esta exigencia junto con otras para poder ejercer el oficio de escribano quedaron recogidas en la Novísima recopilación de las leyes de España, Libro VII, Título XV, Ley III y V. 
al año 1720 llegando hasta 1754. En este examen podemos apreciar un número relativamente alto de mujeres propietarias de estos oficios, ya sean numerarios, de cabildo o de millones, siendo los más numerosos los primeros. De entre ellas destaca una, que aúna en su persona un doble perfil, el de ser mujer y el de pertenecer al estamento nobiliario, nos referimos a la ya mencionada Marquesa de Villena.

Tabla $n^{\circ}$ 1: Escribanías cuya propiedad, o parte de ella, recaían en una mujer. Provincia de Málaga (1751-1754). Málaga capital (1720-1754).

\begin{tabular}{|l|l|}
\hline ANTEQUERA & $\begin{array}{l}\text { María Cueto y Traba. } \\
\text { Propietaria de una escribanía pública. }\end{array}$ \\
\hline BENAMARGOSA & $\begin{array}{l}\text { Ángela Criado y María Criado. } \\
\text { Propietarias de una octava parte cada una, de una } \\
\text { escribanía de cabildo. }\end{array}$ \\
\hline CÁRTAMA & $\begin{array}{l}\text { Josefa Damiana de Anaya. } \\
\text { Propietaria de una escribanía de millones. }\end{array}$ \\
\hline COÍN & $\begin{array}{l}\text { María Benítez del Castillo. } \\
\text { Propietaria de una escribanía de cabildo. }\end{array}$ \\
\hline MÁLAGA & $\begin{array}{l}\text { Antonia López Bueno. } \\
\text { Propietaria de una escribanía del número. }\end{array}$ \\
\hline MÁLAGA & $\begin{array}{l}\text { Juana Caballero. } \\
\text { Propietaria de una escribanía del número. }\end{array}$ \\
\hline MÁLAGA & $\begin{array}{l}\text { María Urbano. } \\
\text { Propietaria de una escribanía del número. }\end{array}$ \\
\hline MÁLAGA & $\begin{array}{l}\text { María de Ávila. } \\
\text { Propietaria de una escribanía del número. }\end{array}$ \\
\hline MÁLAGA & $\begin{array}{l}\text { María de Arias y Linares. } \\
\text { Propietaria de una escribanía del número. }\end{array}$ \\
\hline Ángela Aldana. \\
Propietaria de una escribanía del número.
\end{tabular}


Por todo lo aducido la mujer fue clave, en numerosas ocasiones, dentro de la institución notarial, ya que se presenta como clave de bóveda para muchos hombres que querían acceder a una escribanía. La fémina como hija de escribano heredó en numerosas ocasiones este oficio, y, aunque no podía ejercerlo, sí que podía ser su propietaria, venderlo o designar a un escribano que lo sirviera en el ínterin hasta la mayoría de edad de alguno de sus hijos, o hasta que lo vendiera. Muchas dotes matrimoniales fueron estos oficios, de ahí que muchos hombres vieran en el enlace matrimonial una oportunidad como ninguna otra de poder hacerse con uno de los codiciados escritorios. La mujer como madre ejercía como ama y señora del oficio, nominando a quien fuera oportuno para servirlo hasta la mayoría de edad del hijo. Pero muchos de los escribanos murieron solteros, sin herederos, y su madre como única familia, por lo que en estos casos el escritorio revertía de nuevo a la madre, quien nombraba a algún fedatario en el ínterin o vendía el oficio al mejor postor. La mujer como hermana también tenía su función dentro de esta institución, ya que por herencia podía compartir la titularidad del oficio con sus hermanos, o bien podía ser la heredera de alguno de ellos que no tuviera descendencia. Por lo tanto, la mujer en muchos casos se convirtió en un instrumento para poder acceder a un oficio de escribanía, y en otros muchos ella era la que tomaba las decisiones sobre el devenir de dicho oficio.

\section{BIBLIOGRAFÍA}

Álvarez-Coca, María Jesús (1987). La figura del escribano. Boletín de la ANABAD, n. XXXVII, 4 (octubre-diciembre), pp. 555-564.

Arroyal, Pedro José et al. (1991). Las escribanías públicas de Málaga (1487-1516), Málaga: Universidad de Málaga.

Arroyal, Pedro José et al. (2007). El Notariado en Málaga durante la Edad Moderna. Estructura Organizativa. Málaga: Servicio de Publicaciones Universidad de Málaga, Studia Malacitana.

Arroyal, Pedro José y Ostos, Pilar. (edits.) (2014). Los escribanos públicos y la actividad judicial, III Jornadas sobre el Notariado en Andalucía, 24 y 25de noviembre de 2011. Málaga: Libros Encasa.

Artuña, Roberto (2014). Notariado y documentación notarial en el área central del señorio de los obispos de Oviedo (1291-1389), Tesis doctoral dirigida por Miguel Calleja Puerta, Oviedo: Universidad de Oviedo.

Barco, Lorena (2014). Mujer, poder y linaje en la Baja Edad Media. Una biografía de Leonor Pimentel. Madrid: Ediciones la Ergástula.

Barco, Lorena y Marchant, Alicia (coords.) (2016). "Dicebamus hesterna die...": estudios en homenaje a los profesores Pedro J. Arroyal Espigares y $M^{a}$ Teresa Martín Palma. Málaga: Encasa. 
Blasco, Rosa María (1990). Una aproximación a la institución notarial en Cantabria. Santander: Universidad de Cantabria.

Bono, José (1979). Historia del derecho notarial español. Madrid: Junta de Decanos de Colegios Notariales de España, 2 vols.

Calero, María Isabel (coord.) (1993). Saber y vivir: mujer, antigüedad y medievo. Málaga: Atenea.

Calleja, Miguel (2014). A escribir a la villa: clerecía urbana, escribanos de concejo y notarios públicos en la Asturias del siglo XIII. Historia, Instituciones, Documentos, n. 42, pp. 59-82. DOI: http://dx.doi.org/10.12795/hid.2015.i42.02

Camino, Carmen del (1998), En torno a los escribanos públicos de Ceuta (1580-1700). En Homenaje al profesor Carlos Posac. Ceuta: Instituto de Estudios Ceutíes, vol. II, pp. 223-242.

Carlé, María del Carmen (1980). Apuntes sobre el matrimonio en la Edad Media española. Cuadernos de Historia de España, n. 63-64, pp. 115-177.

Castro, Beatriz (2017). Escribanos y notarios en la España moderna: Balance historiográfico y nuevas perspectivas de investigación. En López, María Amparo y Gallia, Arturo (ed. lit). Itinerarios de investigación histórica y geográfica. Cáceres: Universidad de Extremadura, pp. 69-76.

Cózar, Ramón (2010). "De lo que yo el infrascripto doy fe": los escribanos de la villa de Albacete durante el siglo XVIII. Revista de Historia Moderna, n. 28, pp. 269-299.

Domínguez, María Luisa (2013). El acceso al oficio de escribano público en el Antiguo Reino de Sevilla (siglo XVI). En Funciones y prácticas de la escritura: I Congreso de Investigadores Noveles en Ciencias Documentales. Madrid: Departamento de Ciencias y Técnicas Historiográficas, Universidad Complutense de Madrid; [Escalona, Toledo]: Ayuntamiento de Escalona pp. 57-62.

Domínguez, María Luisa (2016). Las escribanías del antiguo reino de Sevilla bajo el reinado de Felipe II (1556-1598), Tesis doctoral dirigida por Pilar Ostos-Salcedo. Sevilla: Universidad de Sevilla.

Escalante, José (2016). Los escribanos en Antequera (1478-1869). Antequera (Málaga): Exlibric.

Escudero, Luis (2012). Los escribanos manchegos a mediados del siglo XVIII. Una aproximación a su patrimonio agrario. En Pérez, María José y Martín, Alfredo (coords.), Campo y campesinos en la España Moderna; culturas políticas en el mundo hispano. León: Fundación Española de Historia Moderna. Vol. 2, pp. 1337-1347.

Extremera, Miguel Ángel (2011). El ascenso frustrado. De una mesocracia emergente a una burguesía ausente (Córdoba, 1500-1800). Historia y Genealogía, n. 1, pp. 23-39.

Fuster, Francisco (2009). La historia de las mujeres en la historiografía española: propuestas metodológicas desde la historia medieval. Edad Media: Revista de Historia, n. 10, pp. 247-273. 
García, Francisco (2016). Vejez, viudas y soledad rural en la España centro-meridional del siglo XVIII. Studia histórica. Historia Moderna, vol. 38, n. 2, pp. 287-324.

Krauel, Blanca (ed.) (1992). Las investigaciones sobre la mujer. Logros y proyectos. Málaga: Atenea.

Lora, Gloria (2002). Estrategia matrimonial y fiscalidad señorial: las bodas de Isabel de Estúñiga y Fadrique Álvarez de Toledo. Historia, instituciones, documentos, n. 29, pp. 187-216.

Marchant, Alicia (2002). Los escribanos públicos de Málaga bajo el reinado de Carlos I. Málaga: Servicio de Publicaciones de la Universidad de Málaga.

Marchant, Alicia y Barco, Lorena (2017). Participation of women in the notarial public deed of the 16th century. From the constriction of the marital licence to the fullness of widowhood. European Scientific Journal, vol. 13, n. 11, p. 1-17. DOI: http:// dx.doi.org/10.19044/esj.2017.v13n11p1

Mendoza, Eva (2007). Los escribanos de Málaga en el reinado de Felipe IV (16211665). Málaga: Servicio de Publicaciones, Centro de Ediciones de la Diputación de Málaga.

Montojo, Vicente (2008). Las escribanías murcianas en las Reformas de los Borbones. Documenta \& Instrumenta, n. 6, pp. 7-28.

Morant, Isabel (dir.) (2005). Historia de las Mujeres en España y América Latina I. De la Prehistoria a la Edad Media. Madrid: Cátedra.

Moreno, María Amparo et al. (coords.) (2011). El notariado andaluz: institución, práctica notarial y archivos: siglo XVI, II Jornadas sobre el Notariado en Andalucía, Granada, 22 a 24 de abril de 2011. Granada: Universidad de Granada.

Nash, Mary y Tavera García, Susana (coords.) (2003). Las mujeres y las guerras: el papel de las mujeres en las guerras de la edad antigua a la contemporánea. VIII Coloquio internacional de AEHIM. Barcelona: Icaria: Asociación Española de Investigación de Historia de las Mujeres (AEIHM).

Ortego, María Ángeles (2000). Familia y matrimonio en la España del siglo XVIII: ordenamiento jurídico y situación de las mujeres a través de la documentación notarial, Tesis doctoral dirigida por $\mathrm{M}^{\mathrm{a}}$ Gloria Ángeles Franco Rubio. Madrid: Universidad Complutense de Madrid.

Ostos, Pilar y Pardo, María Luisa (eds.) (1995). El notariado andaluz en el tránsito de la Edad Media a la Edad Moderna. Sevilla: Ilustre Colegio Notarial de Sevilla.

Pardo, María Luisa (1993). Exámenes para escribano público en Carmona de 1501 a 1502. Historia. Instituciones. Documentos, n. 20, pp. 303-312.

Piñol, Daniel (coord.) (2015). La 'auctoritas' del notario en la sociedad medieval: nominación y prácticas. Barcelona: Mateo Triguero Rubia.

Puñal, Tomás (2011). El testimonio escrito de la vida privada: scriptores y notarias en San Salvador de Oña (ss. XI-XIV). En Sánchez, R (coord.). San Salvador de Oña: 
mil años de historia. Ayuntamiento de Oña: Fundación Milenario San Salvador de Oña, pp. 292-311.

Rábade, María del Pilar (1992). Las lugartenencias de escribanías como conflicto: un ejemplo de la época de los Reyes Católicos. Espacio, Tiempo y Forma. Serie III, Historia Medieval, n. 5, pp. 211-228. DOI: http://dx.doi.org/10.5944/ etfiii.5.1992.3533

Riesco, Ángel (2003). El notariado castellano bajomedieval (siglos XIV-XV): Historia de esta institución y de la producción documental de los notarios hasta el reinado de Isabel I de Castilla. En II Jornadas cientificas sobre documentación de la Corona de Castilla (siglos XII-XIV). Madrid: Universidad Complutense, pp. 175-225.

Rodríguez, Joaquín (2001). Escribanos públicos en Huelva: los protocolos notariales y el Archivo Histórico Provincial. Huelva en su historia, n. 8, pp. 131-150.

Rojas, Reyes (2004). La memoria de lo privado en lo público: los escribanos públicos sevillanos. Historia, Instituciones, Documentos, n. 31, pp. 573-584.

Sánchez, Ana Belén y Domínguez, Jesús (1999), Las escrituras góticas. En Riesco, Ángel (ed.). Introducción a la paleografía y la diplomática general. Madrid: Síntesis, pp. 111-147.

Segura, Cristina (1992). Valoración historiográfica sobre la historia de las mujeres en el Medievo hispano. Estudis Baleàrics, n. 43, pp. 139-152.

Segura, Cristina (2006). Veinticinco años de historia de las mujeres en España. Memoria y Civilización: anuario de la Universidad de Navarra, n. 9, pp. 85-107.

Segura, Cristina (2008a). Historia de las mujeres en la Edad Media. Medievalismo, n. 18, pp. 249-272.

Segura, Cristina (2008b). La Historia sobre las Mujeres en España. eHumanista, vol. 10, pp. 274-292.

Suárez, Beatriz (2003). Sexualidades: teorías literarias y feministas. Alcalá de Henares: Ayuntamiento de Alcalá de Henares.

Val Valdivieso, María Isabel (coord.) (2004). La historia de las mujeres: una revisión historiográfica. Valladolid: Universidad de Valladolid.

Villalba, Enrique y Torné, E (edits.) (2010). El nervio de la república: el oficio de escribano en el Siglo de Oro. Madrid: Calambur. 